\title{
PERENCANAAN MANAJEMEN LANSKAP ZONASI DESTINASI WISATA BUDAYA KOTA TUA JAKARTA
}

\author{
Rudy Aryanto; Idris Gautama So \\ Management Department, School of Business and Management, BINUS University \\ Jln. KH. Syahdan No 9, Kemanggisan-Palmerah, Jakarta 11480
}

\begin{abstract}
Kota Tua is just like other historical old towns in various cities in developing countries, generally preserved even put to improve simultaneously historic and economic value of sustainable revitalization program which involves all stakeholders. The historical value and the architecture of the Kota Tua Jakarta are no less attractive compred to other cities in the world. Thus, Kota Tua has become a historical mainstay tourism destination objects for Jakarta and has broad potential to bring a lot of domestic and foreign tourists. Study on this research describes the identification of direction of planning and development of landscape management in historical tourism destinations of Kota Tua Jakarta. After conducting various studies and literature, then the spatial obtained existing condition, studies the potential of historical tourism, studies history, typology and building reserves, cultural space and Setup zoning patterns, which can be used for consideration and direction for management zoning landscape historical tourism in Kota Tua Jakarta
\end{abstract}

Keywords: historical tourism, planning, management, landscape zoning

\begin{abstract}
ABSTRAK
Kota Tua seperti kota tua bersejarah lainnya di berbagai kota di negara-negara berkembang, pada umumnya dilestarikan bahkan menempati untuk meningkatkan nilai sejarah dan ekonomi secara bersamaan dari program revitalisasi berkelanjutan yang melibatkan semua pihak. Nilai sejarah dan arsitektur dari Kota Tua Jakarta tidak kalah menarik dibandingkan dengan kota-kota lain di dunia. Jadi Tua Kota telah menjadi andalan sejarah objek tujuan wisata bagi Jakarta dan memiliki potensi besar untuk membawa banyak wisatawan domestik dan asing. Studi dalam penelitian ini menggambarkan identifikasi arah perencanaan dan pengembangan manajemen lanskap dalam tujuan wisata sejarah Kota Tua Jakarta. Setelah melakukan berbagai penelitian dan literatur, kemudian kondisi spasial yang ada diperoleh, studi potensi wisata sejarah, penelitian sejarah, tipologi dan bangunan cagar, ruang budaya dan pola penataan zonasi, yang dapat digunakan untuk pertimbangan dan arah untuk manajemen zonasi lanskap pariwisata sejarah di Kota Tua Jakarta.
\end{abstract}

Kata kunci: pariwisata sejarah, perencanaan, manajemen, zonasi lanskap 


\section{PENDAHULUAN}

Pariwisata saat ini merupakan sektor ekonomi terbesar di dunia. Begitupun halnya di Indonesia. Pariwisata di Indonesia tumbuh menjadi sektor yang dapat diandalkan untuk meningkatkan perekonomian negara selain sektor migas. Dengan berkembanganya keanekaragaman destinasi pariwisata dengan memanfaatkan potensi budaya Indonesia yang sangat kaya menjadikan Indonesia salah satu destinasi utama wisata budaya di ASEAN. Argumentasi tersebut dapat dibuktikan dari angka jumlah perjalanan wisatawan mancanegara (wisman) di Indonesia menurut BPS DKI Jakarta (2011) disebutkan pada tahun 2003 dari 3.690.852 bertumbuh menjadi 7.002.944 di tahun 2010, demikian juga dengan destinasi pariwisata di Jakarta di tahun 2003 sebanyak 1.125.168 bertumbuh menjadi 1.892.866 di tahun 2010. Pertumbuhan ini salah satunya digerakan oleh peningkatan kinerja wisata budaya yang telah meningkatkan kunjungan secara signifikan dari 69.708 di tahun 2006 menjadi 724.082 di tahun 2010 pada objek wisata Museum Sejarah Jakarta yang merupakan bagian dari kawasan wisata budaya Kota Tua Jakarta. Data tersebut merupakan bukti nyata pentingnya pembangunan pariwisata sebagai mesin penggerak ekonomi nasional. Oleh karena itu, pada masa datang pemerintah bertekad untuk mendorong percepatan pembangunan melalui pengembangan produk pariwisata dan pengembangan berbagai fasilitas yang diperlukan.

Salah satu kegiatan pariwisata yang mulai digalakkan sejak beberapa tahun terakhir ini adalah kegiatan wisata sejarah. Kawasan Pariwisata Kota Tua di Provinsi DKI Jakarta memiliki lanskap budaya yang beragam mulai dari kawasan cagar budaya, bangunan-bangunan bersejarah, taman, sungai, perkantoran, perdagangan, dsb. Oleh karena itu, sangat potensial untuk dikembangkan menjadi daerah tujuan wisata di tanah air. Namun, kondisinya saat ini masih belum siap. Diperlukan berbagai pembenahan dan dukungan lintas sektor agar kawasan ini siap "jual” untuk daerah tujuan wisata budaya unggulan.

Pengembangan Destinasi Pariwisata sejarah diarahkan untuk memperoleh peningkatan kualitas dan kompetensi kapasitas pada fasilitas-fasilitas penting yang memiliki nilai lebih sehingga mampu memberikan pengaruh pengembangan wilayah secara berkelanjutan. Prospek strategis sektor pariwisata tersebut tentu menjadi peluang berarti bagi Indonesia khususnya DKI Jakarta sebagai sebuah wilayah yang memiliki kekayaan budaya yang sangat besar dan memiliki keanekaragaman destinasi pariwisata. Sektor pariwisata berperan sebagai penyumbang devisa menjadi salah satu sektor yang diandalkan pemerintah ke depan untuk menjadi pilar pembangunan sektor pariwisata harus digarap secara serius, terarah, dan profesional.

Salah satu pilar destinasi pariwisata budaya unggulan yang dimiliki oleh DKI Jakarta adalah kawasan wisata Kota Tua. Kawasan Kota Tua Jakarta adalah suatu kawasan yang unik dari aspek peninggalan sejarah. Pemda DKI Jakarta juga menetapkan kawasan Kota Tua sebagai kawasan pemugaran dan objek wisata. Sebagai kawasan yang ditetapkan sebagai objek rekreasi/wisata, maka berbagai sektoral yang ada di lingkungan Pemda DKI Jakarta, secara terpadu menangani kawasan Kota Tua ini, baik dari sisi rancangan bangun, prasarana jalan, kebijakan tata ruang, pola sirkulasi kendaraan, pola parkir, penataan aliran sungai, pendestrian, pola hijau, pedagang kaki lima dan serta berbagai pelaksanaan kegiatan kesenian yang terjadwal. Maka disadari oleh segenap pelaku pariwisata di DKI Jakarta tentang pentingnya menyiapkan grand design pengembangan fasilitas bagi destinasi pariwisata budaya Kawasan Kota Tua DKI Jakarta, khususnya dengan melakukan manajemen lanskap dan zonasi wisata budaya yang unggul dan kompetitif.

\section{Kawasan Pariwisata Kota Tua}

Daerah studi Kota Tua merupakan wilayah bangunan bersejarah di perkotaan. Salah satu ciri khas wilayah bangunan bersejarah yang sangat dipengaruhi oleh kondisi keramaian dan mobilitas kota, sehingga relatif mempunyai tingkat ketidakpastian yang cukup tinggi bila dibandingkan dengan daerah 
lainnya. Karakteristik arsitektur masa lalu yang terdiri dari bangunan-bangunan dan kawasan-kawasan cagar budaya berperan dalam merangkai dan menghubungkan sejarah kota Jakarta dari masa lalu ke masa sekarang dan masa yang akan datang. Arsitektur masa lalu ini merupakan bagian yang tidak dapat dipisahkan dari rencana kota. Bangunan-bangunan cagar budaya dan juga kawasan-kawasan cagar budaya tersebar disegala penjuru kota, dengan konsertrasi memanjang dari bagian Utara sampai ke Selatan kota.

Saat ini Jakarta memiliki 4 (empat) kawasan cagar budaya, yaitu: Kota Tua, Menteng, Kebayoran Baru, dan Situ Babakan. Di dalam kawasan-kawasan ini terdapat arsitektur kota dan bangunan-bangunan yang harus dilestarikan. Selain itu, juga banyak terdapat bangunan-bangunan pelestarian yang berada di luar kawasan-kawasan ini. Masing-masing kawasan cagar budaya memiliki panduan khusus yang disesuaikan dengan kondisi dan karakter dari masing-masing kawasan. Panduan ini terutama adalah panduan peruntukkan pemanfaatan ruang-ruang kota dan bangunan-bangunan cagar budaya di Zona Kawasan Cagar Budaya Kota Tua di Jakarta.

Upaya pelestarian di Jakarta didasarkan kepada UU No. 5 tahun 1992 Tentang Benda Cagar Budaya dan Peraturan Daerah No. 9 tahun 1999, yang menggolongkan kawasan cagar budaya menjadi 3 (tiga) golongan, yaitu: kawasan cagar budaya golongan I sampai dengan III dan menggolongkan bangunan cagar budaya menjadi 3 (tiga) golongan, yaitu: bangunan cagar budaya golongan A,B dan C. Pemanfaatan kawasan dan bangunan cagar budaya disesuaikan dengan wujud fisiknya dan perencanaan kota untuk daerah dimana kawasan dan bangunan cagar budaya berada, yang ditentukan oleh Pemda DKI Jakarta. Pemanfaatan barunya disesuaikan dengan kebutuhan masa kini dan akan datang selama cocok dengan wujud fisiknya.

\section{Sejarah Umum Wilayah Wisata Budaya Kota Tua}

Dalam sejarah perkembangan wilayah objek pariwisata budaya Kota Tua, diketahui bahwa sebelum jatuh ke tangan Belanda, Jayakarta, pelabuhan dari pemerintahan Banten, telah menjadi pelabuhan penting di Nusantara maupun kawasan lebih luas, termasuk Asia Tenggara. Setelah dikuasai pada awal abad XVII, VOC merombaknya, dan pembangunannya selain menjadi pelabuhan, juga pusat perdagangan, militer dan pemerintahan, dilanjutkan hingga jaman Penjajahan. Pada abad XVIII, terbentuk menjadi kota di dalam tembok, berbentuk segi empat, dengan bagian utaranya pelabuhan, yang menjadi gerbang masuk ke kota dari arah laut, melalui kanal yang berasal dari Sungai Ciliwung yang diluruskan dan disebut Kali Besar hingga sekarang. Polanya kotak-kotak, tidak terbentuk oleh jalan seperti kota-kota di jaman pertengahan, namun oleh kanal-kanal melintang dan membujur, dengan bangunan-bangunan di tepiannya. Perkembangan kota ke arah selatan, benteng tidak lagi terlalu diperlukan untuk pertahanan, tetap berorentasi ke Kali Ciliwung dengan rumahrumah berhalaman luas di kiri-kananya, membuat Kota Batavia sangat indah dan nyaman hingga mendapat sebutan Ratu dari Timur (Queen of the East). Hingga pusat kota berpindah kea rah selatan pada awal abad XX, Kota Lama Batavia, tetap menjadi pusat pemerintahan, perdagangan, pelayanan dan jasa, bahkan di dalamnya terdapat kantor-kantor dagang internasional.

Kota Jakarta mulanya bernama Batavia, didirikan oleh VOC setelah merebutnya dari Pangeran Jayawikarta kemudian dijadikan pusat pemerintahan kolonial karena potensi topografis antara lain adanya Sungai Ciliwung, menghubungkannya dengan wilayah pedalaman dan secara regional menjadi pelabuhan di Nusantara karena letak geografisnya sangat strategis, bahkan secara internasional, hingga sekarang menjadi Kota Jakarta. Sehingga Jakarta memiliki berbagai peninggalan masa lalu. Peninggalan-peninggalan masa lalu itu, berupa tata ruang, arsitektur, dan konstruksi pelabuhan, perkantoran, fasilitas sosial, perdangan termasuk berbagai bank sangat unik dan indah, saat ini menghadapi masalah kehancuran, sejalan dengan dinamika kota Jakarta, berkembang dengan sangat cepat. Tidak sedikit bangunan bersejarah di Kota Tua hilang, musnah dan menghadapi masalah keruntuhan karena tidak terawat, tidak dihuni dan tidak dipakai. 


\section{METODE PENELITIAN}

Metode yang digunakan dalam penelitian ini adalah metode deskripsi konseptual pada penelusuran sejarah dan lanskap destinasi wisata, yang terdiri dari studi lanskap, tapak, literatur, wawancara dengan narasumber, dan pengamatan lapang (survey). Kegiatan yang dilakukan adalah persiapan rencana dasar, inventarisasi lanskap dan tapak (pengumpulan data) dan analisis (evaluasi), dan tahap desain perencanaan konseptual.

Perencanaan lanskap destinasi wisata budaya yang dimaksud adalah sesuai dengan pendapat dari Simonds dan Starke (2006) yang diartikan sebagai suatu bentang alam dengan karakteristik tertentu, yang dapat dinikmati oleh seluruh indera manusia. Lanskap terdiri dari lanskap alami dan lanskap buatan. Lanskap alami terdiri dari hutan, sungai, kolam, rawa, bukit pasir, padang rumput, gunung, danau, laut, bukit, jurang, lembah dan padang pasir. Sedangkan lanskap buatan merupakan suatu lanskap alami yang telah dimodifikasi oleh manusia untuk menunjang aktivitas manusia tanpa merusak lanskap tersebut.

Peralatan dan bahan yang digunakan dalam studi ini yaitu: Global Positioning System (GPS) yang telah tersedia pada berbagai media internet seperti googlemaps dan ina-geospasial untuk menentukan koordinat beberapa tempat di lokasi penelitian serta untuk proses peta survey topografi dan kontur. Serta software untuk mengolah data yaitu Arcview untuk mengolah data gambar rencana lanskap, potongan, dan berbagai gambar yang berhubungan dengan spasial.

Dengan perencanaan lanskap kawasan destinasi wisata menggunakan pendekatan perencanaan lanskap zonasi untuk meningkatkan fungsi kawasan sebagai kawasan wisata, studi ini menghasilkan perencanaan konseptual, berupa gambar rencana lanskap, detail deskripsinya dan laporan tertulis.

\section{HASIL DAN PEMBAHASAN}

\section{Kondisi Umum Wilayah Pariwisata}

Berdasarkan kajian sejarah tersebut, sebagian besar dari kawasan Sunda Kelapa dan Zona Pariwisata Kawasan Cagar Budaya Kota Tua adalah cikal bakal Kota Tua, yaitu kota yang pada masa kolonial berada di dalam dinding benteng, yang ditinggali sebagian besar oleh Bangsa Belanda. Kawasan ini dahulu dibatasi oleh Sungai Ciliwung di sebelah timur, kanal Stadt Buiten Gracht sebelah barat (kini Sungai Krukut) di sebelah barat, kanal Stadt Buiten Gracht di sebelah selatan (kini Jalan Jembatan Batu dan Jalan Asemka), laut di utara (termasuk Pelabuhan Sunda Kelapa). Di luar kawasan ini terdapat permukiman-permukiman lain yang bersama-sama kota di dalam benteng merupakan Kawasan Cagar Budaya Kota Tua seperti apa yang tercakup pada Peraturan Gubernur Provinsi Daerah Khusus Ibu kota Jakarta Nomor 34 Tahun 2005. Kawasan cagar budaya ini adalah kawasan seluas sekitar 846 Ha yang terletak di Kotamadya Jakarta Utara dan Kotamadya Jakarta Barat.

\section{Kondisi Lingkungan dan Bangunan di Kota Tua}

Berdasarkan kajian tata ruang, Kota Lama Batavia yang dibangun VOC hingga akhir abad XIX, terbagi menjadi lima, yaitu: Benteng Batavia (Kasteel), Batavia Timur, Batavia Barat, Batavia Selatan di luar benteng. Kampung Cina (Het Chine Kwartier), "Markas Jawa” (Javasche Kwartier) (Kawasan Luar Batang), dan Water Kasteel (musnah). Kawasan Kota Tua, keadaan masa kini dengan pebagian kondisi saat ini, terkait dengan nilai-nilai sejarah bagian Kota Tua, nilai sejarah ruang arsitektur dengan kondisi saat ini. 
Legenda destinasi pariwisata sejarah Kota Tua saat ini: Kawasan Inti Kota Tua, sangat bersejarah dengan bangunan masih berfungsi, namun ada yang sudah dirombak dan hilang; Kawasan Kota Tua, dengan bangunan di dalamnya ada yang masih baik, sedang dan banyak yang masih berdiri, namun dalam bahaya runtuh; Kawasan Kota Tua, yang bangunan-bangunannya sudah berubah karena dirombak.

Dari bagian-bagian tersebut, berdasarkan kajian sebelumnya, kondisi bangunan saat ini terbagi dalam beberapa kategori: sudah musnah (telah dibongkar diganti bangunan baru); hampir musnah (bagian-bagiannya sudah mulai runtuh); masih utuh namun kosong tidak terpelihara dalam waktu tidak lama akan mulai runtuh; masih cukup baik, namun kosong tidak digunakan (juga akan rusak bila tidak digunakan); dan masih baik, terpelihara dan digunakan.

Adapunkondisi lanskap dan bangunan bersejarah yang ada di kawasan inti Kota Tua dapat digambarkan pada ilustrasi manajemen lanskap berikut ini.

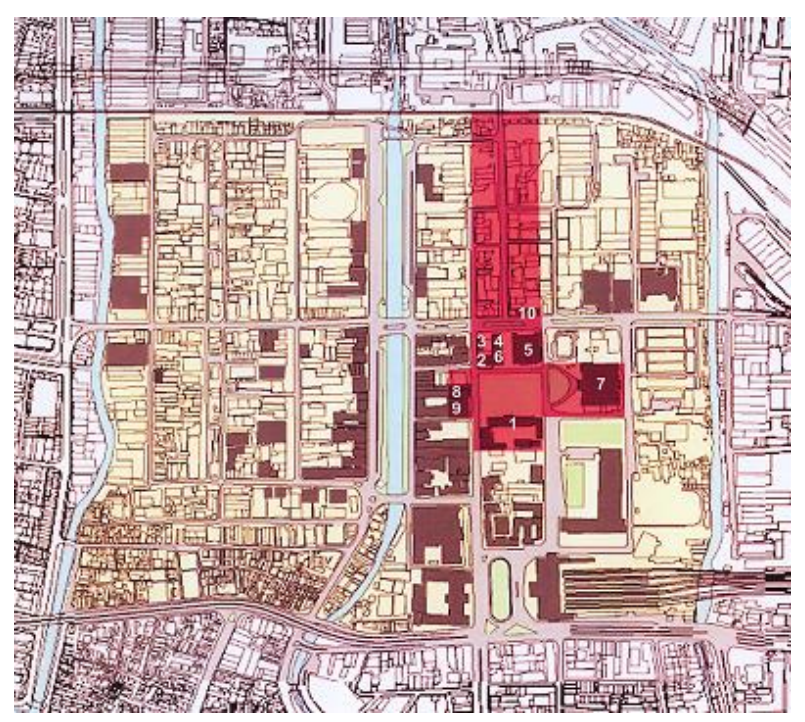

Gambar 1 Kondisi Lanskap Kawasan Inti Kota Tua Arah Pengembangan dan Penataan Wilayah Wisata Budaya Kota Tua

Berdasarkan analisis terhadap peta-peta dan referensi-referensi sejarah, didapatkan beberapa jejak-jejak masa lampau yang masih dapat ditelusuri untuk menemukan keterkaitan antara sejarah, arsitektur, dan kota Batavia.

\section{Ketertarikan antara Sejarah, Arsitektur, dan Kota Batavia}

Untuk menentukan batas wilayah Kota Tua Jakarta, dapat kita gunakan keadaan kota Batavia sebelum 1814 yaitu Gubernur Jenderal Daendels. Pembongkaran tembok kota Batavia menjadi momentum penting, karena sesudah zaman ini, perluasan kota Batavia melampaui areal benteng ke arah timur, barat dan selatan. Batas wilayah kota benteng ini adalah bagian barat (kali Krukut). Pada bagian selatan adalah areal Stadhuis, Museum Bank Mandiri dan Gedung BI yang lama. Pada bagian timur adalah (kali Ciliwung). Pada bagian utara meliputi kawasan pelabuhan Sunda Kelapa, Kampung Luar Batang. Sebagian besar artefak pada periode ini adalah peninggalan zaman VOC (dibubarkan 1799 karena bangkrut). 
Oleh karena itu, ciri-ciri lingkungan sejarah di areal ini banyak menunjukkan kekuatan politik kolonial VOC yang berorientasikan politik dagang militer melalui kekuatan maritimnya. Peniruan secara mentah-mentah bangunan-bangunan dari Nedherland tanpa mempertimbangkan aspek iklim dan budaya setempat menjadi salah satu cirinya. Namun demikian, perlu disadari bahwa di dalam wilayah ini juga hadir bangunan-bangunan kolonial bersejarah periode sesudah VOC yang cukup dominan dan juga harus dilindungi.

Politik kolonial membagi masyarakat menjadi tiga kekuatan, yaitu yang pertama adalah masyarakat Eropa yang jumlahnya sedikit namun menjadi kekuatan utama yang mendominasi. Masyarakat ini tinggal di bagian dalam tembok, khususnya di bagian inti. Yang kedua adalah masyarakat Asia lain khususnya Cina dan Arab. Sebagian kecil masyarakat ini masih ada yang tinggal didalam benteng, namun sesudah tahun 1740 (peristiwa pembantaian orang Cina), mereka ditempatkan di sebelah selatan benteng yang sekarang terkenal sebagai daerah Pecinan Glodok. Yang ketiga adalah masyarakat pribumi, yang jumlahnya paling banyak namun menurut politik kolonial, mereka (pribumi) menjadi warga kelas tiga. Masyarakat ini tersebar di luar benteng dan utamanya tinggal di kampungkampung.

\section{Pola Ruang Kota}

Pola kota Batavia periode VOC banyak dipengaruhi oleh teori kota ideal dan praktis yang digagas oleh Simon Stevin, seorang ahli matematika sekaligus perencana kota abad XVII dari Belanda. Menurut teori ini, unsur gereja sangat penting di dalam sebuah kota Eropa karena menjadi pengikat hubungan antara manusia dan Tuhannya. Kota juga harus mempunyai pertahanan militer sekaligus menampung fungsi komersial. Kekuatan komersial ini dapat dimaksimalkan dengan memanfaatkan potensi perairan, serta memanfaatkan pola grid untuk memaksimalkan banyak fasade, untuk keuntungan komersial. Dalam kota ideal ini, Stevin mengatur wilayah publik, hunian, kanal dan grid kotak agar wilayah publik dapat terlindungi tanpa menghilangkan kebebasan individu. Selain itu peran kanal sangat penting dalam penyusunan kota kolonial. Bangunan-bangunan publik seperti kastil, gereja, sekolah, rumah sakit, pasar serta tempat persinggahan para pedagang asing diatur sedemikian rupa agar tidak terkesan dominan maupun tidak terabaikan. Hal ini dilakukan dengan cara: perletakan bangunan-bangunan tersebut dalam satu aksis memanjang di salah satu sisi/bagian kota; perletakan bangunan-bangunan tersebut menyebar di setiap sisi/bagian kota, dengan tetap disusun dalam satu aksis memanjang.

\section{Konsep Tata Ruang}

Dalam skema Stevin, tembok kota menjadi unsur perlindungan penting, dimana pada jarakjarak tertentu terdapat bastion-bastion pengawas. Kastil menjadi simbol kekuasaan sekaligus pertahanan kota.

\section{Sirkulasi}

Alur sirkulasi darat di dalam kota Batavia juga sudah tertata rapih. Alur kendaraan kereta dan kuda berupa jalan-jalan utama dan umum dari material bukan asphalt. Pada pergantian abad ke 20, pemerintah kota Batavia sempat membuat alur trem di wilayah ini. Sementara itu pemerintah kota (abad ke 19) juga membuat alur pedestrian yang menerus. Hal ini sangat dimungkinkan karena sebagian besar bangunan di dalam areal ini mempunyai Garis Sempadan Bangunan 0, dan jalan setapak (pedestrian) terdapat di bagian muka banguanan (sebagian besar dibangun pada masa VOC) serta pedestrian yang masuk ke dalam muka bangunan (archade) yang dibangun pada masa sesudah VOC. 


\section{Elemen Ruang Kota}

Sebagian elemen ruang kota dapat disebutkan antara lain adalah lampu-lampu jalan antik, spot-spot tempat air minum, serta bangku-bangku taman. Untuk areal hijau, dari foto-foto yang kita analisis tidak terlalu banyak. Wilayah kota tua ini pada zaman dahulu sudah merupakan daerah yang cukup panas terutama di siang hari, karena pengaruh iklim laut. Konsentrasi pohon-pohon berada di daerah sepanjang Kali Besar, dan daerah sekitar benteng.

Pada bagian inti ruang kota, terdapat dua jalur utama yaitu: jalur yang merepresentasikan kekuasaan politik kolonial (darat). Jalur darat berbentuk aksis utara-selatan menghubungkan Kastil Batavia yang menjadi kediaman Gubernur Jenderal Amsterdaam Port (lokasinya sekarang sebelah selatan jalan tol) sampai ke Stadhuis. Lingkungan di sekitar Kastil Batavia (daerah jalan Tongkol sekarang) adalah wilayah kota kolonial tertua dengan galangan kapal dan pergudangan VOCnya. Wilayah ini dihubungkan dengan sebuah jalan yang menjadi penghubung ke pusat ruang publik kota di selatannya. Ruang publik, stadhuisplein (sekarang Taman Fatahillah) yang berada di depan Stadhuis menjadi ruang terbuka utama dimana di sekelilingnya berdiri bangunan-bangunan penting yang berhubungan dengan pusat kekuasaan kolonial Batavia, yaitu di sebelah selatan terdapat stadhuis, di sebelah barat terdapat Gereja (Hollandsche Kerk) dan monument Jan Pieterzoen Coen dan sebelah timur terdapat Gedung Pengadilan (Raad van Justitie). Sementara itu di sebelah utara terdapat kantorkantor pemerintah.

Jalur kedua adalah jalur yang merepresentasikan dominasi ekonomi, sosial dan budaya kolonialisme, yaitu dimulai dari arah laut (pelabuhan Sunda Kelapa), menerus ke sepanjang Groote Rivier (Kali Besar) sampai ke selatan (hinterland). Jalur ini menjadi jalur keluar masuk barang (ekspor dan impor) bagi kota Batavia, dan merupakan jalur air karena mengandalkan perahu-perahu kecil sebagai alat transportasi dan pengangkut utama. Sepanjang jalur ini berdiri bangunan-bangunan pergudangan dan perusahaan milik Belanda, Cina dan Arab. Jalur ini menjadi jalur interaksi (antartindak) sosial budaya yang kental, karena disini terjadi interaksi antara 3 kekuatan masyarakat (Eropa, Asia, dan Pribumi).

\section{Tipologi Bangunan}

Pada kawasan yang dikaji ini dapat disimpulkan ini terdapat empat tipologi bangunan, yang dibedakan sesuai masyarakat dan zamannya, yaitu: pertama, bangunan Masyarakat Kolonial Eropa; bangunan-bangunan periode VOC (abad XVI - XVII), yang berciri arsitektur periode Jaman Pertengahan Eropa, dengan kesan tertutup, sedikit bukaan, jendela besar-besar tanpa teritisan dan tanpa serambi (verandah); bangunan-bangunan periode Negara Kolonial (mulai abad 19), terutama gaya-gaya Colonial Indische (atap-atap teritisan, verandah, jendela-jendela krepyak) dan Neo Klasik Eropa (Yunani, Romawi dll); bangunan-bangunan modern kolonial (abad XX), seperti bangunan bergaya Art Deco dan Art Nouveau. Kedua, bangunan masyarakat Cina; bangunan Cina oriental dari masyarakat Cina berbentuk shop houses (rumah toko) dengan gaya Cina selatan. Sebagian ada yang bercampur dengan gaya kolonial Eropa. Ketiga, bangunan masyarakat pribumi; bangunan masyarakat pribumi sebagian besar berada di luar benteng ( di daerah kampung-kampung), berbentuk panggung dan rumah-rumah yang sudah menempel di tanah dengan dinding bahan-bahan alami. Masyarakat pribumi yang berkelas (zaman abad 19) membangun rumahnya dengan lebih permanen, bergaya kolonial Indische. Keempat, bangunan modern Indonesia; arsitektur dalam kategori ini, dibangun sesudah masa kemerdekaan, terutama bangunan-bangunan umum yang bergaya internasional. 


\section{SIMPULAN}

Berdasarkan Rencana Induk Kota Tua Jakarta (DTK, 2007), di tengah-tengah Kawasan Cagar Budaya Kota Tua ditetapkan zona inti, yaitu area yang memiliki nilai sejarah yang lebih bernilai, yang dahulunya sebagian besar adalah kota di dalam dinding. Kawasan Cagar Budaya Kota Tua dibagi menjadi 5 zona, yaitu: kawasan Sunda Kelapa, kawasan Fatahillah, kawasan Pecinan, kawasan Pekojan, dan kawasan Peremajaan. Seperti dalam gambar peta (gambar 2) berikut ini.
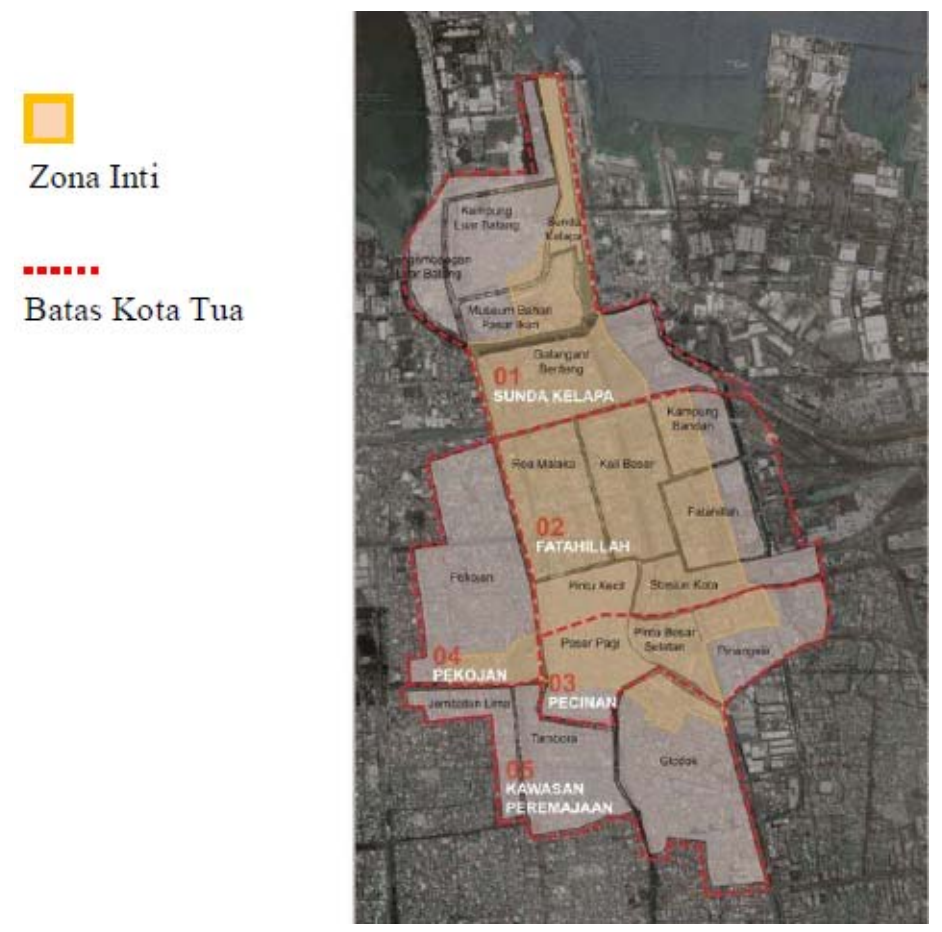

Gambar 2 Peta Manajemen Perencanaan Zonasi Kawasan Kota Tua Jakarta

\section{Zona Pariwisata Kawasan Cagar Budaya Kota Tua Masa Lalu}

Zona Pariwisata Kawasan Cagar Budaya Kota Tua pada masa penjajahan Belanda sampai dengan abad ke XIX adalah bagian selatan dari kawasan di dalam dinding kota yang dibatasi oleh Sungai Ciliwung di sisi timur, Sungai Krukut (Jelakeng) di sisi barat, Jalan Jembatan Batu dan Jalan Asemka di sisi selatan, serta kawasan Pasar Ikan di sisi utara. Pada masa-masa akhir era kolonial Belanda, kawasan ini merupakan pusat bisnis (CBD) kota Batavia dengan konsentrasi kegiatan perdagangan dan jasa di sepanjang Sungai Kali Besar, dan pemerintahan di sekitar Taman Fatahillah.

Kawasan ini ditandai oleh jalan dan sungai/kanal yang membentuk blok-blok berupa grid kota dengan 2 (dua) taman/ plaza, yaitu Taman Fatahillah yang menjadi pusat kegiatan publik dan Taman Beos yang dikelilingi oleh kantor-kantor besar dan Stasiun KA. Di sepanjang Kali Besar terdapat perusahaan dagang dan pelayaran.Blok-blok di belakang Kali Besar ditempati oleh hunian dan bangunan pergudangan.

Bangunan-bangunan di Zona Pariwisata Kawasan Cagar Budaya Kota Tua pada saat ini terdiri dari 3 (tiga) tipe yaitu: bangunan besar yang berdiri sendiri pada satu blok kota atau lebih dari setengah deret yang bersama-sama membentuk satu blok kota. Bangunan-bangunan ini tingginya 
sekitar 2 sampai dengan 3 lantai dengan jarak lantai ke lantai sekitar 4 meter. Keunikan arsitektur kota kawasan ini adalah letak bangunan yang menempel langsung ke jalan atau ruang terbuka/taman/plaza. Di kawasan yang dikaji ini dapat disimpulkan ini terdapat empat tipologi bangunan, yang dibedakan sesuai masyarakat dan zamannya, yaitu: Bangunan masyarakat kolonial Eropa (Colonial Indische, Neo Klasik Eropa, Art Deco, dan Art Nouveau), Bangunan masyarakat Cina (Gaya Cina Selatan dan campuran dengan gaya kolonial Eropa), Bangunan masyarakat pribumi (Colonial Indische), dan Bangunan modern Indonesia (International Style).

\section{Penggolongan Lingkungan Cagar Budaya}

Berdasarkan kepada beberapa kriteria yang ada di Peraturan Daerah No. 5 tahun 1999, Zona Pariwisata Kawasan Cagar Budaya Kota Tua, dibagi menjadi 3 (tiga) golongan kawasan cagar budaya, yaitu: Lingkungan cagar budaya Golongan I berada di sekitar Taman Fatahillah dan Jalan Cengkeh. Kawasan Taman Fatahillah, termasuk Jalan Cengkeh dahulu bernama Prinsen Straat (sumbu Amsterdam Poort - Stadhuis), merupakan kawasan yang urgen untuk tetap dilestarikan. Lingkungan ini didominasi oleh bangunan-bangunan cagar budaya golongan A. Jalan Cengkeh dan Taman Fatahillah dahulu merupakan aksis yang merepresentasikan kekuasaan politik kolonial (jalur darat). Bagian-bagian yang sudah sangat berubah di dalam bagian ini, dikembalikan seperti keadaan aslinya.

Lingkungan cagar budaya Golongan II berada di luar lingkungan I. Dahulu, Kali Besar merupakan aksis yang merepresentasikan kekuasaan ekonomi, sosial dan budaya kolonialisme (jalur air). Kawasan sepanjang Kali Besar melebar ke timur sepanjang Kali Besar Timur 3 di selatan ke arah barat Jalan Malaka, sekitar sebelah selatan Balai Kota temasuk BNI Kota, sekitar Taman Beos, termasuk lingkugan ini. Pada lingkungan ini terdapat konsentrasi bangunan-bangunan cagar budaya golongan B dan beberapa bangunan cagar budaya golongan A, Toko Merah, Gedung BI dan Gedung Bank Mandiri. Dalam lingkungan ini, seharusnya diambil kebijakan agar bangunan-bangunan cagar budaya di dalamnya dapat diselamatkan dan dilestarikan.

Lingkungan cagar budaya Golongan III berada diluar Lingkungan Golongan I dan II, yaitu area yang berdekatan dengan Sungai Ciliwung di sisi timur dan area di dekat Sungai Krukut (Jelakeng) di sisi barat. Pada lingkungan ini terdapat beberapa bangunan yang masuk dalam kategori bangunan cagar budaya golongan B. Sedangkan mayoritas bangunan pada lingkungan ini adalah bangunan bukan bangunan cagar budaya.

\section{DAFTAR PUSTAKA}

Aryanto. (2003). Manajemen Objek Ekowisata Pesisir yang Berkelanjutan dalam Rangka Otoomi Daerah. Jurnal Ilmiah Pariwisata dan Lingkungan. Center for Tourism and Environmental Studies. Jakarta.

BPS Provinsi DKI Jakarta. (2011). Jakarta Dalam Angka. Katalog BPS 1102001.31

DTK. (2007). Rencana Induk Pengembangan Pariwisata Kota Tua Jakarta.

Perda No 9 tahun 1999 tentang Ketentuan Pelestarian dan Pemanfaatan Bangunan-bangunan Cagar Budaya di DKI Jakarta

Peraturan Gubernur Provinsi Daerah Khusus Ibu kota Jakarta Nomor 34 Tahun 2005 
Peraturan Pemerintah Republik Indonesia nomor 10 tahun 1993 Tentang Pelaksanaan Undang-Undang nomor 5 tahun 1992 Tentang Benda Cagar Budaya

Simonds and Starke. (2006). Landscape Architecture. New York: McGraw-Hill.

Undang-Undang Republik Indonesia nomor 5 tahun 1992 Tentang Benda Cagar Budaya 